lương mẫu lớn hơn về đa hình rs36211723 và mối liên quan của đa hình này với BCTPĐ trong tương lai. Chúng tôi khuyến nghị mở rộng nghiên cứu, kết hợp với dữ liệu lâm sàng để đánh giá rõ hơn tác động của của đa hình này tới biểu hiện BCTPĐ trên quần thể người Việt Nam.

\section{KẾT LUÂ̂N}

Chúng tôi đã xây dựng được quy trình phân tích đa hình rs36211723 trên mẫu máu toàn phần và áp dụng thành công với 10 mẫu nghiên cứu. Kết quả này sẽ là cơ sở cho các nghiên cứu tiếp theo về đa hình rs36211723 và đột biến gen MYBPC3, phục vụ cho chẩn đoán phát hiện sớm bệnh cơ tim phì đại trên thực tiễn.

Lời cảm ơn. Chúng tôi trân trọng cảm ơn sự tài trợ của Đại học Quốc gia Hà Nội cho đề tài mã sổ QG.18.60 để thực hiện nghiên cứu này.

\section{TÀI LIỆ THAM KHẢO}

1. Maron, B.J., et al. (2018). Global Burden of Hypertrophic Cardiomyopathy.JACC Heart Fail, 6 (5): p. 376-378.

2. Semsarian, $C_{\text {., }}$ et al. (2015). New perspectives on the prevalence of hypertrophic cardiomyopathy.J Am
Coll Cardiol,65(12): p. 1249-1254.

3. Maron, B.J., et al. (1995).Prevalence of hypertrophic cardiomyopathy in a general population of young adults. Echocardiographic analysis of 4111 subjects in the CARDIA Study. Coronary Artery Risk Development in (Young) Adults.Circulation, 92 (4): p. 785-9.

4. Maron, B.J., et al. (2018). Clinical Course and Management of Hypertrophic Cardiomyopathy. $N$ Engl J Med, 379 (7): p. 655-668.

5. Tanjore, R.R., et al.(2008). MYBPC3 gene variations in hypertrophic cardiomyopathy patients in India. Can J Cardiol, 24 (2): p. 127-30.

6. Calore, C.,et al. (2015). A founder MYBPC 3 mutation results in $\mathrm{HCM}$ with a high risk of sudden death after the fourth decade of life.J Med Genet, 52 (5): p. 338-47.

7. Elliott, P.M., et al. (2014). 2014 ESC Guidelines on diagnosis and management of hypertrophic cardiomyopathy: the Task Force for the Diagnosis and Management of Hypertrophic Cardiomyopathy of the European Society of Cardiology (ESC).Eur Heart J, 35 (39): p. 2733-79.

8. Tran Vu, M.T., et al. (2019). Presence of Hypertrophic Cardiomyopathy Related Gene Mutations and Clinical Manifestations in Vietnamese Patients With Hypertrophic Cardiomyopathy.Circ J, 83 (9): p. 1908-1916.

\title{
NGHIÊN CỨU IN VITRO: SO SÁNH TÍNH KHÁNG MỎI CHU KỲ CỦA CÁC HỆ THỐNG TRÂM QUAY WAVEONE GOLD VÀ RECIPROC
}

\section{TÓM TẮT}

Mục tiêu: Nghiên cứu so sánh đặc tính kháng mỏi chu kỳ của hai hệ thống trâm NiTi mới đã có mặt ở thị trường Việt Nam: WaveOne Gold (WO Gold; Dentsply Maillefer, Ballaigues, Switzerland) và Reciproc (VDW, Munich, Germany) có cùng chế độ quay qua lại. Đối tượng và phương pháp: Thử nghiệm nghiên cứu in vitro trên 08 trâm WO Gold Primary có kích thước 25 độ thuôn 7\% (25/0.07); và 08 trâm Reciproc R25 (25/0.08). Trâm được cho quay trong ống tủy nhân tạo cong $90^{\circ}$ cho đến khi gãy. Cả hai nhóm đều được điều khiển bằng cùng một máy nội nhavới chế độ quay qua lại dành riêng cho mối nhóm là WAVEONE ALL (tốc độ 350 vòng/phút) và RECIPROC ALL (tốc độ 300 vòng/phút). Thời gian từ khi bắt đầu quay đến khi gãy được ghi nhận lại. Giá trị thể hiện tính kháng mỏi chu kỳ là số vòng quay được của trâm cho đển khi gãy, được tính bằng cách nhân tốc độ quay với thời gian quay. Kết quả: Số vòng quay được cho đến khi

*Đai hoc Y Dược TP. Hồ Chí Minh

Chiu trách nhiệm chính: Lê Hoàng Lan Anh

Email: Ihlanh@ump.edu.vn

Ngày nhận bài: 3/1/2021

Ngày phản biện khoa học: 2/2/2021

Ngày duyệt bài: $1 / 3 / 2021$

\section{Lê Hoàng Lan Anh*, Phạm Văn Khoa*}

gãy của hệ thống trâm WO Gold Primary $(801,06 \pm$ $62,71)$, cao hơn có ý nghĩa so với hệ thống trâm Reciproc R25 $(648,41 \pm 31,65)$. Kết luần: Hệ thống trâmWO Gold Primary có tính kháng mỏi chu kỳ cao hơn với hệ thống trâm Reciproc R25.

Tư khóa: Tính kháng mỏi chu kỳ, quay qua lại

\section{SUMMARY}

\section{LABORATORY COMPARISON OF CYCLIC FATIGUE RESISTANCE OF WAVEONE GOLD AND RECIPROC FILE SYSTEMS}

Objectives: To compare the fatigue resistance of two new NiTi file systems in Vietnam: WaveOne Gold (WO Gold; Dentsply Maillefer, Ballaigues, Switzerland) and Reciproc (VDW, Munich, Germany) which has the same reciproccating motion mode. Materials and methods: An in vitro comparision of cyclic fatigue test of 08 WO Gold Primary (25/0.07) and 08 Reciproc R25 (25/0.08) was performed in a 90-degree curved artificial canal until failure. Both groups were controlled by a motor with reciprocating motion mode for each group: WAVEONE ALL (has a speed of 350 rpm) and RECIPROC ALL (has a speed of $300 \mathrm{rpm}$ ). The time to failure was recorded. The number of cycles to failure (NCF) for each file was calculated by multiplying the time by the rotational speed. NCF represented cycle fatigue resistance of files. Results: 
WO Gold Primary files had significantly higher NCF $(801,06 \pm 62,71)$ than Reciproc R25 (648,41 \pm 31,65). Conclusion: WO Gold Primary fileswere associated with a significantly higher cyclic fatigue resistance than Reciproc R25 files in a 90-degree curved artificial canal.

Key words: Cyclic fatigue resistance, reciprocating motion

\section{I. ĐẶT VẤN ĐỀ}

Giai đoạn tạo dạng, sửa soạn và làm sạc hống tủy là một trong những giai đoạn quan trọng nhất trong toàn bộ quá trình điêu trị nội nha, ảnh hưởng quan trọng đến thành công hay thất bại của nội nha. Rất nhiều loại dụng cụ, vật liệu đã được ra đời nhằm giúp công việc tạo dạng, sửa soạn và làm sạc hống tủy nhanh chóng, hiệu quả hơn. Một trong những cuộc cách mạng về dụng cụ cho giai đoạn tạo dạng đó là sự ra đời của dụng cu quay máy và quay tay làm bằng Nickel-Titanium (NiTi). Dụng cụ quay NiTi đã rút ngắn rất nhiều thời gian và làm giảm sự mệt mỏi của bác sĩ điều trị.

Dưng cụ quay NiTi có nhiều ưu thế hơn so với các dụng cụ câm tay bằng thép không rỉ: mêm dẻo hơn, hiệu quả cắt cao hơn, nhanh hơn, và tạo được ống tuỷ thuôn và ít có khả năng dịch chuyển ống tuỷ hơn $(2,3)$.

Tuy nhiên, dụng cụ NiTi vẫn có khả năng gãy trong khi quay, chủ yểu do lực gây biến dạng mỏi (uốn) có tính chu kỳ; xoắn trong khi xoay hay kết hợp cả hai khi xoay trong hệ thống ống tuỷ.

Theo nghiên cứu của Sattapan và cộng sự, trong các trường hợp gãy trâm, gãy do mỏi chu kỳ chiếm $44,3 \%{ }^{(6)}$.

Ngay từ lúc bắt đâu kỷ nguyên mới của nội nha hiện đại, rất nhiêuu hãng sản xuất đã giới thiệu những thế hệ trâm NiTi mới khác nhau với mục tiêu nâng cao tính kháng mỏi chu kỳ của dụng cụ.

Hiện nay, trên thế giới đã có nhiều nghiên cứu so sánh tính kháng mỏi chu kỳ của các hệ thống trâm, nhưng qua nhiêu năm phát triển, rất nhiêu nhà sản xuất đã liên tục giới thiệu ra thị trường rất nhiều dụng cụ mới với thiết kế và chế đô quay đa dang, vì vây việc so sánh tính kháng mỏi chu kỳ của các hệ thống trâm mới vẫn luôn là vấn đề được quan tâm.

Trên cơ sở đó, chúng tôi tiến hành nghiên cứu này với mục tiêu so sánh tính kháng mói chu kỳ của hai hệ thống trâm mới đã có mặt ở thị trường Việt Nam: WaveOne Gold (WO Gold; Dentsply Maillefer, Ballaigues, Switzerland) và Reciproc (VDW, Munich, Germany) có cùng chế độ quay qua lại. Qua đó, nghiên cứu này cung cấp cho bác sĩ Răng Hàm Mặt những thông tin cân thiết để nhằm đạt được sự an toàn cao nhất trong việc tạo dạng ống tuỷ trong điều trị nội nha.

\section{II. ĐỐI TƯƠ'NG VÀ PHƯƠNG PHÁP NGHIÊN CỨU}

2.1. Thiết kế nghiên cứu. Nghiên cứu in vitro, người đánh giá độc lập.

2.2. Đối tượng nghiền cứu. 08 trâm quay WO Gold Primary có kích thước 25, độ thuôn $7 \%$ (25/0.07); 08 trâm quay Reciproc R25 (25/0.08). Tất cả đêuu ở chiêu dài $21 \mathrm{~mm}$, chưa qua sử dụng, bề mặt trâm nguyên vẹn, không quan sát thấy bất kỳ lỗi kỹ thuật nào trên kính hiển vi quang hoc.

2.3. Phương tiện nghiên cứu. Máy nội nha Wave One (Dentsply Maillefer, Ballaigues, Switzerland)

Một ống tủy cong nhân tạo được mô tả bởi Lopes HP và cộng sự (2010) (4), làm bằng thép không gỉ, là một ống hình trụ, có đường kính trong 1,4mm; tổng chiều dài 19 mm; một đoạn cong nằm giữa hai đoạn thẳng, có bán kính $6 \mathrm{~mm}$; chiêuu dài của đoạn cong là $9 \mathrm{~mm}$; chiêu dài hai đoạn thẳng lân lượt là $3 \mathrm{~mm}$ và $7 \mathrm{~mm}$ (hình 1 )

Một hệ thống gôm một bản kim loại hình chữ nhật và một trục dọc. Ống tủy thép được giữ cố định trên bản kim loại. Trục dọc có kẹp để giữ cố định tay khoan nội nha. Trục dọc này có thể di chuyển trên tấm kim loại để thay đổi vị trí của tay khoan nội nha (hình 2)

Dâu tổng hợp RP7® (Selleys, Australia)

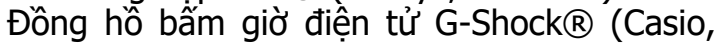
Japan) có độ chính xác 1/100 giây

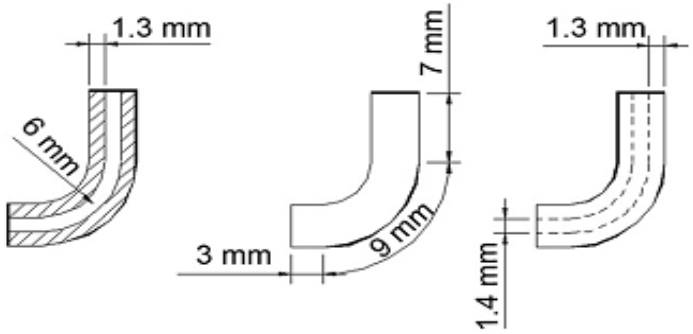

Hình 1. Bản vẽ kỹ thuật của ống tưy nhân tạo "Nguồn: Lopes và CS, 2010"(4)

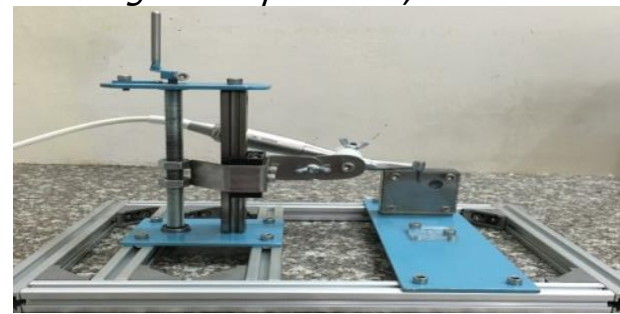

Hình 2. Hệ thống bản kim loại để giữ tay khoan và ống tủy thép

Điều chỉnh vị trí tay khoan nội nha sao cho trục của trâm quay trùng với trục của đoan thẳng của ống tủy thép. Đưa trâm quay vào trong ống tủy thép cho đến hết chiều dài rồi cố 
định tay khoan nội nha. Trong toàn bộ thử nghiệm, ống tủy thép luôn được bôi một lớp dầu tổng hợp để làm giảm ma sát của trâm quay đối với thành ống tủy và để hạn chế sự phát sinh nhiệt. Hai nhóm WO Gold Primary và Reciproc R25 được sử dụng bởi máy nội nha WaveOne với chế độ quay dành riêng cho mỗi nhóm lần lượt là WAVEONE ALL (có tốc độ quay 350 vòng/phút) và RECIPROC ALL (có tốc độ quay 300 vòng/phút) (hình 3).

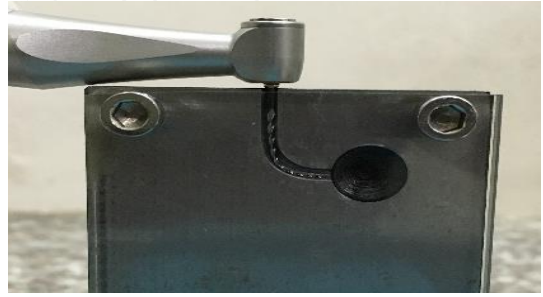

Hình 3. Trâm nôi nha được đưa vào ống tưy thép

Mỗi trâm ở từng nhóm được quay trong ống tủy thép cho đến khi trâm gãy. Thời gian từ khi bắt đâu quay đến khi gãy được ghi lại bằng đồng hồ bấm giờ điện tử có độ chính xác $1 / 100$ giây.

Giá trị thể hiện tính kháng mỏi chu kỳ là số vòng quay được của trâm cho đến khi gãy, được tính bằng cách nhân tốc độ quay với thời gian quay.

2.4. Xử lý và phân tích số liệu. Sử dụng phần mềm SPSS 22.0 để phân tích số liệu. Dùng phép kiểm $\mathrm{t}$ cho hai mẫu độc lập để so sánh số vòng quay được đến khi gãy giữa hai nhóm với mức ý nghĩa của $\mathrm{p}<0,05$.

\section{KẾT QUẢ NGHIÊN CỨU}

Giá trị nhỏ nhất, giá trị lớn nhất, giá trị trung bình và độ lệch chuẩn của số vòng quay được đến khi gãy được thể hiện trong bảng 1 . Nghiển cứu sử dụng phép kiểm $t$ để so sánh giá trị trung bình của hai mẫu độc lập có phân phối chuẩn.

Bảng 1. Kết quả thử nghiệm tính kháng mỏi chu $k \dot{y}$.

\begin{tabular}{|c|c|c|c|}
\hline \multirow{2}{*}{ Nhóm } & \multicolumn{3}{|c|}{ Số vòng quay được đến khi gãy } \\
\cline { 2 - 4 } & $\begin{array}{c}\text { Giá trị } \\
\text { nhọ } \\
\text { nhất }\end{array}$ & $\begin{array}{c}\text { Giá trị lớn } \\
\text { nhất }\end{array}$ & $\begin{array}{c}\text { Trung bình } \\
\text { 士 Độ lệ̂ch } \\
\text { chuẩn }\end{array}$ \\
\hline $\begin{array}{c}\text { WO Gold } \\
\text { Primary }\end{array}$ & 712,95 & 896,00 & $801,06 \pm$ \\
62,71 \\
\hline $\begin{array}{c}\text { Reciproc } \\
\text { R25 }\end{array}$ & 603,85 & 688,85 & $\begin{array}{c}648,41 \pm \\
31,65\end{array}$ \\
\hline
\end{tabular}

- Phép kiểm $t$ cho hai mấu độc lập, $p<0,05$

Số vòng quay được cho đến khi gãy của WO Gold Primary có giá trị trung bình là 801,06 (độ lệch chuẩn 62,71 ), cao hơn so với Reciproc R25 có giá trị trung bình 648,41 (độ lệch chuẩn $31,65)$. Sự khác biệt này có ý nghĩa thống kê ( $p$ $<0,05)$.

\section{BÀN LUÂN}

Kết quả cho thấy WO Gold có tính kháng mỏi chu kỳ cao hơn Reciproc. Kết quả này tương tứ với nhiều nghiên cứu khác trên thế giới. Topcuoglu và cộng sự (2016) kết luận rằng trâm quay dùng một lần Wo Gold có tính kháng mỏi chu kỳ cao hơn trâm WaveOne và Reciproc khi quay trong một ống tuỷ cong nhân tạo hình chữ $S^{(8)}$. Nghiên cứu của Plotino và cộng sự (2012) cho thấy trâm Reciproc có tính kháng mỏi chu kỳ cao hơn tram WaveOne ${ }^{(5)}$. Nghiên cứu của Keskin và cộng sự (2017) cho thây trâm WO Gold có tính kháng mỏi chu kỳ cao hơn Reciproc nhưng thấp hơn Reciproc Blue(1).

Sự khác nhau về tính kháng mỏi chu kỳ của hai nhóm này có thể được giải thích do hai yếu tố: cấu tạo của hợp kim chế tạo dụng cụ; thiết diện cắt ngang và thiết kế của dụng cụ.

Thứ nhất, các hệ thống trâm được cấu tạo từ các loại hợp kim khác nhau. Reciproc cấu tạo từ hợp kim M-wire, trong khi WO Gold được sản xuất từ dây vàng và xử lý nhiệt sau khi gia công ${ }^{(8)}$. Cải tiến về hợp kim chế tạo giúp dụng cụ mềm dẻo hơn, tăng mức an toàn và làm giảm khả năng gãy dụng cụ trong khi sử dụng.

Thứ hai, cả thiết diện cắt ngang và thiết kế dụng cư đều có thể là một trong những nguyên nhân dẫn đến sự khác biệt về tính kháng mỏi chu kỳ. WO Gold Primary có thiết diện hình chữ nhật, tiếp xúc với thành ống tủy ở một hoặc hai điểm; và Reciproc có thiết diện hình chữ $S$, tiếp xúc với ống tủy ở hai điểm. Nhiều nghiên cứu trên thế giới đã đề câp về sự ảnh hưởng của thiết diện cắt ngang trâm NiTi lên tính kháng mỏi chu kỳ của chúng $(1,5,7,8)$.

WO Gold Primary có thiết diện cắt ngang dạng hình chữ nhật, có tâm của thiết diện cắt ngang của dụng cụ tại một vị trí không trùng với tâm của trục của toàn thể dụng cụ ở vị trí đó. Đây được gọi là thiết kế bù trừ, lệch tâm hay thiết kế thiết diện cắt ngang thiếu - không đủ để dụng cụ tiếp xúc cùng lúc bốn đỉnh của hình chữ nhật mà chỉ tiếp xúc với thành ống tuỷ ở một hoặc hai điểm. Thiết kế đặc biệt này giúp dụng cụ có chuyển động tịnh tiến. Với các đặc điểm thiết kế trên, Wo Gold Primary có các ưu điểm sau: giảm tiếp xúc giữa phần tác dụng của dụng cụ với vách ống tuỷ do đó làm giảm nguy cơ bắt vít vào ống tuỷ và làm giảm lực tác động lên dụng cụ, giảm nguy cơ gãy dụng cụ̣(7).

Nghiên cứu của Plotino và cộng sự (2012) cho thấy Reciproc có tính kháng mỏi chu kỳ cao hơn WaveOne dù được làm từ cùng loại dây $\mathrm{M}$ wire. WaveOne có thiết diện cắt ngang tam giác 
lồi, tiếp xúc với thành ống tuỷ ở ba điểm; trong khi Reciproctiếp xúc với ống tủy ở hai điểm. Các tác giả cho rằng Reciproc có tính kháng mỏi chu kỳ cao hơn WaveOne là vì Reciproc có điểm tiếp xúc với thành ống tuỷ ít hơn, thiết diện nhỏ hơn, thì tính kháng mỏi sẽ tăng ${ }^{(5)}$. Như vậy, thiết kế của trâm là một yếu tố quan trọng ảnh hưởng đến tính kháng mỏi chu kỳ.

\section{KẾT LUÂN}

Chúng tôi thực hiện nghiên cứu tính kháng mỏi chu kỳ của hai hệ thống trâm WO Gold Primary và Reciproc R25 bằng cách tiến hành cho dụng cụ quay trong ống tủy cong làm bằng thép không rỉ cho đến khi gãy. Kết quả cho thây WO Gold Primary có tính kháng mỏi chu kỳ cao hơn với Reciproc R25. Sư khác biệt này có ý nghĩa thống kê.

\section{TÀI LIÊU THAM KHẢO}

1. Cangül Keskin, Uğur Inan, MuratDemiral, AliKeles. Cyclic Fatigue Resistance of Reciproc Blue, Reciproc, and WaveOne Gold Reciprocating Instruments. Journal of Endodontics 2017, 43 (8), 1360-1363

2. Chen JL, Messer HH. A comparison of stainless steel hand and rotary nickel-titanium instrumentation using a silicone impression technique. Australia Dental Journal 2002; 47:12-20

3. Kim HC, Kwak SW, Cheung GSP, Ko DH. Cyclic fatigue and torsional resistance of two new nickeltitanium instruments used in reciprocation motion: Reciproc versus WaveOne. Journal of Endodontic 2012, 38(4): 541-544

4. Lopes HP, Elias CN, Vieira VTL, Moreira EJL et al. Effects of Electropolishing Surface Treatment on the Cyclic Fatigue Resistance of BioRace NickelTitanium Rotary Instruments. Journal of Endodontics 2010, 36 (10): 1653-7.

5. Plotino G, Grande NM, Testarelli L, Gambarini G. Cyclic fatigue of Reciproc and WaveOne reciprocating instruments. International Endodontic Journal 2012, 45 (7): 614-618

6. Sattapan B, Nervo GJ, Palamara JE, Messer HH. Defects in rotary nickel-titanium file after clinical use. Journal of Endodontics 2010, 26: 161-5

7. Tong Fangli, Keiichiro Maki, Shunsuke Kimura, Miki Nishijo, Daisuke Tokita, Arata Ebihara and Takashi Okiji. Assessment of mechanical properties of WaveOne Gold Primary reciprocating instruments. Dental Materials Journal 2019, 38(3): 490-495

8. Topcuoglu H.S., Duzgun S., Akti A., Topcuoglu G. Laboratory comparison of cyclic fatigue resistance of WaveOne Gold, Reciproc and WaveOne files in canals with a double curvature. International Endodontic Journal 2016, 50 (7): 713-717.

\title{
TUÂN THỦ ĐIỀU TRI TĂNG HUYẾT ÁP BẰNG THUỐC CỦA BỆNH NHÂN NGOẠI TRÚ TẠI KHOA TIM MẠCH PKĐK HOÀN MỸ SÀI GÒN
}

\author{
Trần Đức Sĩ ${ }^{*}$, Nguyễn Hùng**, \\ Phan Kim Mỹ*, Nguyễn Thanh Hiệp*
}

\section{TÓM TẮT}

Đắt vấn đề: Một trong những khuyến cáo để tăng hiệu quả điều trị tăng huyết áp là nâng cao việc tuân thủ điêu tri nhằm giảm các biến chứng của bệnh. Nghiên cứu này nhằm mục đích ghi nhận tỉ lệ tuân thủ điêu trị bằng thuốc của người bênh đang điều trị ngoại trú tăng huyết áp tại Khoa tim mạch Phòng khám đa khoa Hoàn Mỹ Ṡài Gòn. Đối tướng và phương pháp: Người bệnh được chọn ngấu nhiên, được phỏng vấn trực tiếp và thu thẩp số liêu theo bảng thu thập số liệu soạn sẵn. Sự tuân thủ điều trị dùng thuốc được ghi nhận bằng cách hỏi trực tiếp bênh nhân và gián tiếp bằng cách dùng thang điểm MMAS-8. Kết quả: Trong tổng số 387 bệnh nhân, có

\footnotetext{
*Trường Đại hoc Y khoa Phạm Ngọc Thạch

**Phòng khám Đa khoa Hoàn Mỹ Sài Gòn

Chịu trách nhiệm chính: Trần Đức Sĩ,

Email: sitd@pnt.edu.vn

Ngày nhận bài: 3/1/2021

Ngày phản biên khoa học: 29/1/2021

Ngày duyệt bài: 26/2/2021
}

355 (91,73\%) bênh nhân tự nhân định mình điều trị đều. Điểm trung bình mức đô tuân thủ điều trị theo thang điểm MMAS-8 trong nghiên cứu của chúng tôi là 5,77 (ĐLC:1,52). Các lý do không dùng thuốc tăng huyết áp theo đúng chỉ định nổi bật là quên dùng thuốc hàng ngày theo đúng chỉ định (39,28\%). Các yếu tố liên quan có ý nghĩa thống kề với điểm MMAS-8 gồm tuổi bệnh nhân $(p<0,01)$, nhóm bênh nhân có HA đạt mục tiêu điều trị thì tuân thủ dùng thuốc (điểm trung bình MMAS-8) cao hơn so với nhóm chưa đạt mục tiêu điều trị $(p=0,03)$. Bên cạnh đó, bênh nhân được chẩn đoán tăng huyết áp càng lâu thì điềm tuân thủ dùng thuốc càng cao, điểm số MMAS-8 còn tương quan với tổng lượng thuốc bênh nhân dùng $(p<0,01)$ cũng như một số yếu tố dịch tễ khác. Kêtt luân: Cân phải nâng cao kiến thức và nhân thức của bênh nhân về bệnh THA để nâng cao mức độ tuân thủ điều trị dùng thuốc và cả không dùng thuốc. Cần lưu ý nhắc nhở tuân thủ dùng thuốc đối với những bệnh nhân trẻ, những trường hợp chưa đat $\mathrm{HA}$ mục tiêu, mắc bênh chưa lâu hoặc đang phải dùng nhiều thuốc cùng lúc.

Tư khóa: Tăng huyết áp, tuân thủ điều trị, thuốc hạ áp, MMAS-8. 